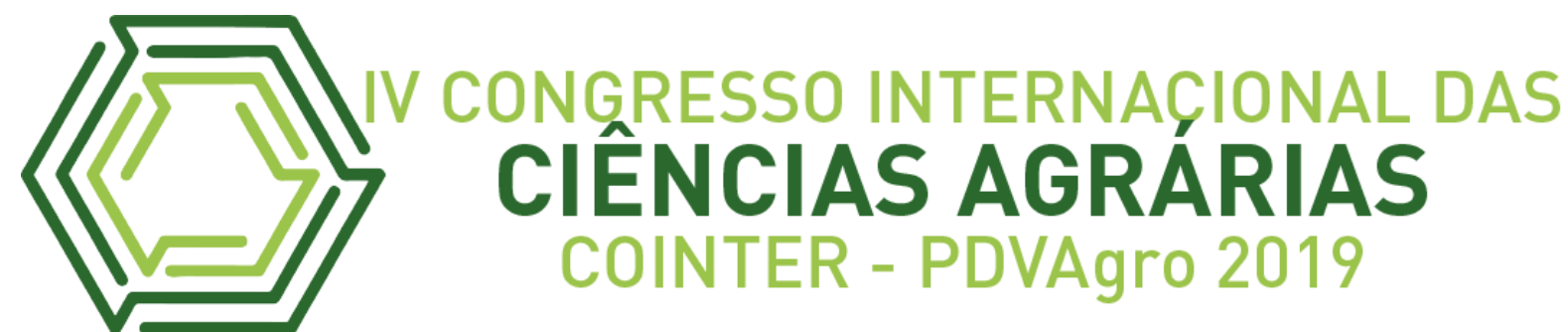

\title{
PRODUÇÃO DE PIGMENTOS POR Monascus purpureus CCT 3802 UTILIZANDO FARELO DE CEVADA COMO SUBSTRATO
}

\section{PRODUCCIÓN DE PIGMENTOS POR Monascus purpureus CCT 3802 USANDO SALVADO DE CEBADA COMO SUSTRATO}

\section{PIGMENT PRODUCTION BY Monascus purpureus CCT 3802 USING BARLEY BRAN AS A SUBSTRATE}

\author{
Apresentação: Comunicação Oral
}

\begin{abstract}
Karla Beatriz Rodrigues de LIMA ${ }^{1}$; Cássia Luisa dos Santos PEDROSA ${ }^{2}$; José Renato da SILVA $^{3}$ Thaís Aparecida Espíndola da SILVA ${ }^{4}$; Daniele Silva RIBEIRO ${ }^{5}$
\end{abstract}

\section{DOI: https://doi.org/10.31692/2526-7701.IVCOINTERPDVAgro.2019.0102}

\begin{abstract}
Resumo
A cor é um dos atributos mais importantes em alimentos e bebidas, sendo uma característica decisiva para a compra e consumo destes. Os aditivos responsáveis por conferir e intensificar as cores dos alimentos são os corantes, que podem ser naturais ou sintéticos. Há um grande estímulo para a obtenção de novos pigmentos ou corantes naturais, que podem ser obtidos, por exemplo $_{2}$ a partir de fungos filamentosos, como os do gênero Monascus, utilizado em países asiáticos há séculos para a produção de corante vermelho. Assim, o objetivo deste trabalho consistiu em produzir pigmentos a partir da fermentação submersa do Monascus purpureus CCT 3802 utilizando o farelo de substrato e duas fontes externas de nitrogênio, por meio de um planejamento fatorial $2^{3}$, variando a fonte de carbono (farelo de cevada) e as fontes de nitrogênio (glutamato monossódico e glicina). A caracterização do farelo de cevada também foi realizada, com a execução das análises de umidade, cinzas, pH, atividade de água, acidez total titulável, lipídeos, proteínas, fibras em detergente neutro e carboidratos totais por diferença, todas em triplicata, para maior confiabilidade. Da caracterização foi possível confirmar os altos teores de fibras em detergente neutro $(62,86 \pm 9,21)$, proteínas $(8,04 \pm 0,72)$, lipídeos $(9,40 \pm 1,35)$, cinzas $(4,10 \pm 0,13)$ e carboidratos totais $(8,97 \pm 0,00)$. Estas características auxiliam no metabolismo da cepa estudada, produzindo metabólitos secundários, como pigmentos, de alto interesse. Com relação à obtenção dos pigmentos, as maiores produções ocorreram nos ensaios que continham a maior quantidade do farelo de cevada e glicina, sendo esta a fonte de nitrogênio com maior influência no meio estudado $\left(11,74 \mathrm{UA}_{510}\right)$, comprovando a efetividade deste resíduo da indústria cervejeira na obtenção de pigmentos alimentares de cor vermelha, sendo uma forma alternativa de tratamento e reaproveitamento.
\end{abstract}

\footnotetext{
${ }^{1}$ Graduanda em engenharia de alimentos, UFRPE, Garanhuns, karla_beatrizrlima@hotmail.com

${ }^{2}$ Graduanda em engenharia de alimentos, UFRPE, Garanhuns, cassiapedrosa141@gmail.com

${ }^{3}$ Graduando em engenharia de alimentos, UFRPE, Garanhuns, j_renatosilva123@hotmail.com

${ }^{4}$ Graduanda em engenharia de alimentos, UFRPE, Garanhuns, thaais.espindola@hotmail.com

${ }^{5}$ Doutora em Ciência e Tecnologia de Alimentos, UFRPE, Garanhuns, ribeirodanieles@gmail.com
} 
Palavras-Chave: Pigmentos Monascus, resíduo agroindustrial, fermentação submersa. Resumen

El color es uno de los atributos más importantes en alimentos y bebidas, siendo una característica decisiva para su compra y consumo. Los aditivos responsables de controlar e intensificar los colores de los alimentos son los colores, que pueden ser naturales o sintéticos. Existe un gran incentivo para obtener nuevos pigmentos o colorantes naturales, que se pueden obtener, por ejemplo, de hongos filamentosos como Monascus, utilizados en los países asiáticos durante siglos para producir colorantes rojos. Por lo tanto, el objetivo de este trabajo fue producir pigmentos a partir de la fermentación sumergida de Monascus purpureus CCT 3802 utilizando el salvado de sustrato y dos fuentes externas de nitrógeno, a través de un diseño factorial de $2^{3}$, variando la fuente de carbono (harina de cebada). y fuentes de nitrógeno (glutamato monosódico y glicina). La caracterización de la harina de cebada también se realizó realizando humedad, cenizas, $\mathrm{pH}$, actividad del agua, acidez titulable total, lípidos, proteínas, fibra de detergente neutral y carbohidratos totales mediante análisis de diferencia, todo por triplicado, para mayor fiabilidad A partir de la caracterización fue posible confirmar el alto contenido de fibras de detergente neutro (62.86 \pm 9.21$)$, proteínas $(8.04 \pm 0.72)$, lípidos $(9.40 \pm$ $1.35)$, cenizas $(4.10 \pm 0.13)$ y carbohidratos totales $(8.97 \pm 0.00)$. Estas características ayudan en el metabolismo de la cepa estudiada, produciendo metabolitos secundarios, como los pigmentos, de gran interés. En cuanto a la obtención de los pigmentos, los mayores rendimientos se produjeron en los ensayos que contenían la mayor cantidad de harina de cebada y glicina, que es la fuente de nitrógeno con mayor influencia en el entorno estudiado $(11,74$ UA 510 ), lo que demuestra la efectividad de este residuo de la cebada. industria cervecera para obtener pigmentos rojos alimenticios, siendo una forma alternativa de tratamiento y reutilización.

Palabras clave: Pigmentos Monascus, residuos agroindustriales, fermentación sumergida.

\begin{abstract}
Color is one of the most important attributes in food and beverages, being a decisive feature for their purchase and consumption. The additives responsible for checking and intensifying the colors of food are the colors, which can be natural or synthetic. There is a great incentive to obtain new natural pigments or dyes, which can be obtained, for example, from filamentous fungi such as Monascus, used in Asian countries for centuries to produce red dye. Thus, the objective of this work was to produce pigments from the submerged fermentation of Monascus purpureus CCT 3802 using the substrate bran and two external nitrogen sources, through a $2^{3}$ factorial design, varying the carbon source (barley meal). and nitrogen sources (monosodium glutamate and glycine). The characterization of barley meal was also performed by performing moisture, ash, $\mathrm{pH}$, water activity, total titratable acidity, lipid, protein, neutral detergent fiber and total carbohydrates by difference analyzes, all in triplicate, for greater reliability. From the characterization it was possible to confirm the high contents of neutral detergent fibers (62.86 $\pm 9.21)$, proteins $(8.04 \pm 0.72)$, lipids $(9.40 \pm 1.35)$, ashes $(4.10 \pm 0.13)$ and total carbohydrates $(8.97 \pm 0.00)$. These characteristics help in the metabolism of the studied strain, producing secondary metabolites, such as pigments, of high interest. Regarding the obtaining of the pigments, the highest yields occurred in the trials that contained the largest amount of barley meal and glycine, which is the nitrogen source with the greatest influence on the studied environment $\left(11,74 \mathrm{UA}_{510}\right)$, proving the effectiveness of this residue from barley. brewing industry to obtain red food pigments, being an alternative form of treatment and reuse.
\end{abstract}


Keywords: Monascus pigments, agro-industrial waste, submerged fermentation.

\section{Introdução}

A cor é um dos primeiros atributos sensoriais decisivos para a escolha de determinado

alimento. É a partir deste parâmetro e a forma como será apresentada que poderá causar aceitabilidade ou não para a compra e o consumo de alimentos e bebidas. Os corantes são os aditivos responsáveis por conferir e intensificar a cor dos produtos alimentícios e, dentre os seus diversos tipos, destacam-se os naturais, devido os seus benefícios e procedência confiável, sendo capazes de influenciar na aceitação do produto final.

Os corantes ou pigmentos naturais podem originar-se de insetos, plantas e microrganismos. Esta última categoria vem ganhando espaço na indústria de alimentos, devido a sua procedência, segurança e possibilidade de produção de forma sustentável. Dentre os microrganismos capazes de produzir pigmentos alimentícios, é possível evidenciar as espécies do fungo filamentoso Monascus. Este é cultivado principalmente em países asiáticos e é capaz de produzir pigmentos com cores que variam entre o vermelho, laranja e amarelo, e podem vir a apresentar atividade antioxidante, ao contrário de pigmentos artificiais.

Atrelado a este fato, é possível utilizar determinados resíduos agroindustriais como substrato para a produção de pigmentos naturais oriundos do fungo Monascus e, com isso, contribuir para minimizar os danos que tais resíduos podem vir a causar ao meio ambiente. A cevada, por exemplo, resíduo da indústria cervejeira pode apresentar grande potencial para esta produção em particular, devido a sua composição química rica em fibras, proteínas e lipídeos, que estimula o metabolismo do fungo estudado.

Com base nas informações apresentadas, este trabalho teve como objetivo obter pigmentos vermelhos extracelulares produzidos pelo fungo filamentoso Monascus purpureus CCT 3802, vistas a avaliar o potencial do farelo de cevada como substrato em fermentação submersa, bem como a influência de duas fontes externas de nitrogênio, glutamato monossódico e glicina, por meio de planejamento fatorial.

\section{Fundamentação Teórica}


A cor pode ser considerada como um dos atributos mais admiráveis quando se trata de produtos do gênero alimentício. Ela é capaz de influenciar a preferência do consumidor e despertar a sua vontade em consumir determinado produto (MARTINS et al., 2016).

Este parâmetro também pode ser capaz de influenciar na percepção do sabor, e é devido à esta capacidade que faz desta característica um dos principais indicadores de qualidade na avaliação do consumidor no momento da compra do alimento. Diante disso, já foi observado que alimentos nutritivos, seguros e com boa relação custo-benefício podem até ser oferecidos, entretanto, se o mesmo não for visualmente atraente, sua venda será prejudicada. Os aditivos responsáveis por conferir e intensificar as cores nos alimentos são os corantes. Estes pigmentos possuem importância nítida do ponto de vista sensorial, pois dependendo de sua origem, podem desempenhar papéis como compostos bioativos nos alimentos, bem como apresentar potenciais benéficos e promissores à saúde do consumidor (DAMODARAN; PARKIN, 2018).

Os corantes alimentícios podem ser classificados como naturais ou sintéticos. Apesar da grande utilização da classe dos sintéticos em alimentos industrializados, estimulados principalmente por sua estabilidade ao processamento e custos mais baixos, seu uso está associado às dúvidas relacionadas à sua procedência e confiabilidade à saúde, ocasionando numa crescente proibição destes aditivos em países desenvolvidos, fazendo com que o mercado de pigmentos naturais se torne amplo e favorável (CONSTANT; STRINGHETA; SANDI, 2002).

Segundo Schiozer e colaboradores (2007), as limitações dos corantes sintéticos, bem como a proibição de diversos corantes vermelhos, têm estimulado o estudo e desenvolvimento de pigmentos naturais para a aplicação em alimentos. Pela crescente demanda de novas cores e de novos métodos de obtenção, surgem pesquisas tanto para o descobrimento de novas fontes, quanto para otimizar a estabilidade de pigmentos naturais já existentes.

Em contrapartida, os pigmentos naturais podem ser obtidos a partir de insetos, plantas ou microrganismos. Estes, em sua maioria, são sensíveis à fatores como luz, presença de metais, calor, oxigênio e pH, onde a intensidade da cor está diretamente relacionada à boas condições de armazenamento, manipulação e práticas de fabricação no qual os alimentos são submetidos (MARTINS et al., 2016).

Em termos de produção, os pigmentos naturais mais vantajosos são os de origem microbiana, quando comparados aos extraídos de vegetais ou animais, devido a sua boa velocidade de crescimento, tornando-o industrialmente competitivo (BABITHA, 2009). Dentre 
os microrganismos produtores, fungos filamentosos do gênero Monascus são grandes apostas para o desenvolvimento e obtenção destes pigmentos, onde a partir de substratos simples e provenientes de resíduos agroindustriais de baixo custo, são capazes de produzir metabólitos secundários estáveis, com cores que variam entre o laranja, amarelo e vermelho, benéficos à saúde do consumidor graças a sua capacidade antioxidante a partir da sua produção de forma sustentável.

Para que a obtenção de pigmentos ocorra de forma potencial, é necessário que além do substrato, haja uma fonte de nitrogênio apropriada ao meio de cultivo, com o objetivo de suplementar o meio estudado (OLIVEIRA, 2017). De acordo com Carvalho e colaboradores (2003), as fontes externas de nitrogênio utilizadas para potencializar a fermentação do Monascus variam de acordo com o tipo de produção desejada. Estas fontes podem variar de nitrogênio inorgânico (amônio e nitratos), até glutamato monossódico e glicina em cultivos submersos. O glutamato monossódico, por sua vez, é um aminoácido não essencial utilizado na indústria de alimentos como realçador de sabores. A glicina, entretanto, também é um aminoácido que o organismo utiliza para criar proteínas necessárias para seu bom funcionamento.

Diversos substratos são estudados para o crescimento do Monascus. Este fator é importante pois determinará se a obtenção de pigmentos ocorrerá de forma apropriada, através da fermentação sólida ou líquida. Os resíduos agroindustriais de baixo custo são uma aposta para tal aplicação. Durante seus experimentos, Srianta et al., (2016) obtiveram pigmentos a partir do Monascus purpureus utilizando arroz, milho, grão de sorgo inteiro e descascado, além do farelo de sorgo por meio de fermentação submersa, comprovando que resíduos comuns e de baixo custo são de fato úteis para uma produção eficaz.

A indústria cervejeira é um segmento da área de alimentos em expansão. Ela por sua vez, é responsável por resíduos que ocasionam desequilíbrio ambiental, como o bagaço de malte de cevada. Este resíduo, entretanto, é constituído principalmente por casca de cevada maltada rica em proteínas, fibras e vitaminas, influenciadas graças a origem da cevada, sua forma de obtenção e processamento específico da cerveja (MUSSATO, 2006), além do seu baixo valor agregado, que para a produção de pigmentos utilizando o fungo filamentoso Monascus purpureus é de grande interesse, pois sua composição química estimula seu metabolismo, facilitando a obtenção de metabólitos secundários. 


\section{Metodologia}

Os experimentos foram realizados na Universidade Federal Rural de Pernambuco, Unidade Acadêmica de Garanhuns, sendo conduzidos nos seguintes laboratórios: Laboratório de Biotecnologia, Laboratório de Tecnologia de Cereais e Derivados, Laboratório de Análise de Alimentos (LAAL) e no Laboratório de Nutrição Animal (LANA).

A cepa Monascus purpureus CCT 3802 foi obtida da Fundação André Torsello de Pesquisa e Tecnologia. Uma cultura de estoque foi mantida em tubos inclinados com meio estéril BDA (Batata Dextrose Ágar), a $4^{\circ} \mathrm{C}$ e repicada periodicamente para a execução dos experimentos. A manutenção destas culturas foi realizada em tubos inclinados contendo meio BDA, esterilizados a $121^{\circ} \mathrm{C}$ por 15 minutos, onde uma alçada contendo o fungo foi transferida para os tubos, e submetido a incubação por 10 dias a $30^{\circ} \mathrm{C}$.

A cevada utilizada para a produção de pigmentos foi obtida em uma cervejaria localizada na cidade de Garanhuns-PE e encaminhada para o Laboratório de Cereais. O material foi devidamente higienizado com água corrente e submetido à secagem em estufa, a $120^{\circ} \mathrm{C}$ por 4 horas. Após este procedimento, a cevada foi triturada e peneirada, produzindo então o farelo, utilizado como substrato.

$\mathrm{O}$ substrato foi submetido às seguintes análises físico-químicas de caracterização: $\mathrm{pH}$, atividade de água (Aw), teor de umidade (\%) utilizando secagem direta em estufa a $105^{\circ} \mathrm{C}$, cinzas (\%) por meio da utilização de mufla a $550^{\circ} \mathrm{C}$, acidez total titulável (ATT), teor de lipídios (\%) pelo método da extração direta em Soxhlet, teor de proteínas (\%) por digestão Kjeldahl, teor de fibras em detergente neutro(\%) e carboidratos totais (extrato livre de nitrogênio) por diferença. Para maior confiabilidade, todas as análises foram realizadas em triplicata, de acordo com as metodologias descritas em Instituto Adolfo Lutz (2008) e Detmann et al. (2012).

Para a preparação e obtenção do inóculo utilizados para o processo de fermentação, após dez dias de incubação em meio estéril BDA a $30^{\circ} \mathrm{C}$, os esporos da cepa do Monascus purpureus CCT 3802 foram suspensos em $20 \mathrm{~mL}$ de solução estéril - Tween 80 $0,3 \%(\mathrm{v} / \mathrm{v})$ + água destilada estéril - coletados com o auxílio de uma pipeta capilar de Pasteur. Em frascos Erlenmeyers de $125 \mathrm{~mL}$, foram colocados $25 \mathrm{~mL}$ dos substratos (água destilada estéril (v/v); (m/v) farelo de cevada), suplementados com duas fontes de nitrogênio: glutamato monossódico (GMS) e glicina. Este meio foi submetido a tratamento térmico de $121^{\circ} \mathrm{C}$ por 15 minutos. Após o tratamento térmico, a suspensão da cultura obtida foi transferida para os 
frascos Erlenmeyer contendo os meios de cultivo. Estes foram incubados durante 7 dias, a $30^{\circ}$ C por 160 rpm, na ausência de luz, para posterior análise de produção de pigmentos.

Para verificar a influência do substrato estudado (farelo de cevada) e das fontes externas de nitrogênio (glutamato monossódico e glicina) na produção de pigmentos pelo Monascus purpureus CCT 3802, foi realizado um planejamento fatorial completo $2^{3}$, com repetições de quatro pontos centrais. A codificação então utilizada para níveis alto e baixo, responsável pelas quantidades de substrato, GMS e glicina foi representada por +1 e -1 , respectivamente, com ponto médio representado por 0 .

Ao final da fermentação, o meio foi filtrado através da técnica de filtração a vácuo, fazendo uso de papel filtro quantitativo. O sobrenadante foi centrifugado por $4.500 \mathrm{x} g$ durante 20 minutos. $\mathrm{O} \mathrm{pH}$ final dos pigmentos produzidos foram aferidos e encaminhados para a quantificação. A produção dos pigmentos extracelulares por cepas Monascus purpureus CCT 3802 foi expressa em Unidade de Absorbância (UA), utilizando espectrofotômetro num comprimento de onda de $510 \mathrm{~nm}$, referente à coloração vermelha.

Após o planejamento estatístico e execução do experimento de produção, os resultados obtidos foram processados no software Statistica 7.0 (StatSoft. Inc., Tulsa, OK, USA), indicando os efeitos estatisticamente significativos $(\mathrm{p}<0,05)$ que auxiliará na otimização dos processos.

\section{Resultados e Discussão}

\section{Caracterização do farelo de cevada para aplicação como substrato}

O substrato utilizado na obtenção dos pigmentos, o farelo de cevada, foi submetido à análises físico-químicas, para o maior entendimento de sua atuação neste processo (Tabela 1).

O percentual de umidade alcançou valores com média de 6,63\%, logo, o substrato encontra-se de acordo com a legislação vigente (BRASIL, 2005), que estabelece que produtos de cereais, farinhas, amidos e farelos devem possuir umidade máxima de $15 \%$. A baixa umidade deve-se principalmente ao processo de secagem no qual o farelo de cevada foi submetido para torna-lo em pó, o que propiciou o seu armazenamento em temperatura ambiente e uma maior conservação.

O valor obtido para a análise de cinzas, indicativa da presença ou não de resíduo mineral no alimento após a incineração de sua matéria orgânica, apresentou uma média de 4,10\% entre as amostras feitas. Na análise feita por Mayer e colaboradores (2007) no material integral, foi 
constatada uma média de 2,45\% para amostras de grãos inteiros de cevada e na amostra descascada de $1,44 \%$, o que evidencia que amostras integrais tem maior teor de matéria mineral. A diferença entre os resultados pode ser dada pela a presença de uma maior presença de matéria inorgânica no farelo de cevada, já que o este, de acordo com Brasil (2005), pode ser processado contendo as cascas do próprio grão da cevada. Para a produção de pigmentos esta análise é importante justamente por mensurar a quantidade de material inorgânico existente no substrato trabalhado, visto que muitos fungos filamentosos, como o Monascus purpureus, tem o seu metabolismo estimulado por essa característica em particular.

$\mathrm{O}$ valor de $\mathrm{pH}$ para o farelo de cevada foi de 5,94 $\pm 0,07$. Valores estudados por Souza et al. (2008) oriundos da caracterização físico-química de farinhas de mandioca ficaram entre 4,54 e 5,47. Em seus estudos, relacionados à caracterização química do resíduo fibroso da indústria cervejeira, Mello, Vergílio e Mali (2013) constataram valores de $\mathrm{pH}$ de 5,73 \pm 0,04, comprovando que o farelo estudado possui acidez próxima. É importante salientar que o $\mathrm{pH}$ do substrato influencia diretamente na atuação do fungo, pois este atua melhor em ambientes com pH próximos a alcalinidade. Deste modo, o farelo de cevada estudado pode ser classificado como alimento pouco ácido, colaborando para o desenvolvimento do fungo e consequentemente, melhor produção de pigmentos extracelulares.

Tabela 1: Caracterização físico-química do farelo de cevada.

\begin{tabular}{lc}
\hline Análises & Resultados \\
\hline Umidade (\%) & $6,63 \pm 0,83$ \\
Cinzas (\%) & $4,10 \pm 0,13$ \\
pH & $5,94 \pm 0,07$ \\
Atividade de água (Aw) & $0,55 \pm 0,03$ \\
Acidez total titulável (ml/g) & $11,85 \pm 0,34$ \\
Lipídeos (\%) & $9,40 \pm 1,35$ \\
Proteínas (\%) & $8,04 \pm 0,72$ \\
Fibras (\%) & $62,86 \pm 9,21$ \\
Carboidratos totais (\%) & $8,97 \pm 0,00$ \\
\hline
\end{tabular}

Fonte: Própria (2019)

O resultado determinado para a atividade de água no farelo de cevada foi de $0,55 \pm 0,03$, podendo ser considerado como alimento de umidade intermediária - alimentos cuja faixa de Aw está entre 0,60 e 0,90 (RIBEIRO; SERAVALLI, 2017), onde o crescimento de 
microrganismos patogênicos é dificultado. Em seus estudos sobre a atividade de água e granulometria em farinhas de trigo, polvilho e trigo moído, Amorim et al. (2016) também constatou valores inferiores de 0,60 em suas análises, 0,54 a 0,60, 0,50 a 0,71 e 0,51 a 0,54, respectivamente, evidenciando a importância de que o farelo de cevada apesar de rico em outros nutrientes, tem uma Aw que proporciona maior vida útil, quando armazenado de forma adequada.

O farelo de cevada apresentou uma média de 9,40\% para o teor de lipídeos. Em sua análise de extrato etéreo (EE), que também determina a gordura bruta ou fração do alimento insolúvel em água, Mayer et al., (2007) constataram valores inferiores a 2,89\% em grãos integrais e descascados de cultivares de cevada. Em contrapartida, Gonçalves e Martins (2014) alcançaram valores que variaram entre $8,64 \%$ e $11,28 \%$ de extrato etéreo em bagaço de malte utilizado como matéria-prima para composto de amido. Os valores foram crescentes assim como o tamanho das partículas (mm) analisadas, comprovando que os valores determinados para o farelo de cevada são pertinentes.

O teor de proteínas do substrato foi de 8,04\%, valor próximo ao encontrado por Olvera e colaboradores (2012) que obteve $8,4 \%$ e entre os valores encontrados por Cordeiro (2011) que estiveram entre $7 \%$ e 13\%, ambos para o grão de cevada. A variação é aceitável, visto que Segundo Mathias et. al. (2014) o conteúdo de proteínas será dependente da espécie do grão utilizado, bem como as condições de moagem e mostura utilizadas no processo de fabricação da cerveja. O teor de proteínas é de suma importância para a produção de pigmentos naturais, pois, por se tratarem de macromoléculas capazes de servir como fonte de energia, são utilizadas pela cepa do Monascus purpureus CCT 3802 auxiliando na obtenção dos pigmentos extracelulares, especialmente os de coloração vermelha, pigmentos nitrogenados.

O farelo apresentou $62,86 \%$ de fibras em detergente neutro (FDN), valor superior encontrado por Cordeiro (2011) para o grão da cevada, que ficou entre 19 e $25 \%$. O valor é esperado, dado que o farelo é oriundo da camada mais externa do grão, que é rica neste nutriente, mas apesar disso, diferente de outros grãos, o conteúdo de fibras da cevada está distribuído no grão por inteiro, casca, embrião e endosperma, isso faz com que mesmo, após a retirada da casca o restante do grão, ainda seja capaz de reter até 50\% do teor de fibras original. Por essa razão o farelo se torna atraente do ponto de vista nutricional para a produção de alimentos com elevados teores de fibra (YALCIN et al., 2007). 
De acordo com Catalani e colaboradores (2003), as fibras alimentares podem ser classificadas em: fibras solúveis (pectinas, gomas, mucilagens e hemiceluloses) e fibras insolúveis (celulose, lignina e algumas hemiceluloses). Seu teor é importante pois alguns fungos filamentosos são capazes de metabolizá-las, auxiliando no processo de produção de pigmentos e obtenção de energia durante o processo.

Com relação a determinação dos carboidratos totais, o valor obtido foi de 8,97\%. É importante salientar que os carboidratos totais correspondem a soma de carboidratos fibrosos, e não fibrosos, que são representados por ácidos orgânicos, pectina, amido, responsáveis pelo fornecimento de energia ao meio (HALL, 2003). Para o Monascus purpureus, este parâmetro é de suma importância, pois está ligado diretamente à sua fonte primária de energia, bem como à produção de metabólitos de grande interesse, como os pigmentos. É possível então determinar que o farelo de cevada estudado apresenta grande potencial como substrato devido à presença destes carboidratos, auxiliando uma boa produção.

\section{Avaliação da produção de pigmentos Monascus utilizando o farelo de cevada como substrato}

A quantificação da produção de pigmentos produzidos pelo Monascus purpureus CCT 3802 utilizando farelo de cevada como substrato e duas fontes externas de nitrogênio (glutamato monossódico e glicina) adicionadas ao meio mostrou-se satisfatória, com resultados relevantes e comprovando houve afinidade pela cepa e substrato, além da forma de cultivo (Tabela 2).

Tabela 2: Matriz do planejamento fatorial $2^{3}$ e quantificação de pigmentos por Monascus purpureus CCT 3802

\begin{tabular}{cccccccc}
\hline & \multicolumn{2}{c}{ Valores codificados } & \multicolumn{3}{c}{ Valores reais } & Absorbância \\
\hline Ensaios & Farelo & GMS & Glicina & $\begin{array}{c}\text { Farelo } \\
(\mathbf{g} / \mathbf{L})\end{array}$ & $\begin{array}{c}\text { GMS } \\
(\mathbf{g} / \mathbf{L})\end{array}$ & $\begin{array}{c}\text { Glicina } \\
(\mathbf{g} / \mathbf{L})\end{array}$ & $\begin{array}{c}\text { Leitura 510 nm } \\
(* \mathbf{U A})\end{array}$ \\
\hline $\mathbf{1}$ & +1 & +1 & +1 & 60 & 10 & 10 & 11,74 \\
$\mathbf{2}$ & +1 & +1 & -1 & 60 & 10 & 0 & 9,40 \\
$\mathbf{3}$ & +1 & -1 & -1 & 60 & 0 & 0 & 3,40 \\
$\mathbf{4}$ & +1 & -1 & +1 & 60 & 0 & 10 & 10,20 \\
$\mathbf{5}$ & -1 & +1 & +1 & 20 & 10 & 10 & 5,31 \\
$\mathbf{6}$ & -1 & -1 & -1 & 20 & 0 & 0 & 2,28 \\
$\mathbf{7}$ & -1 & -1 & +1 & 20 & 0 & 10 & 6,56
\end{tabular}




\begin{tabular}{lccccccc}
$\mathbf{8}$ & -1 & +1 & -1 & 20 & 10 & 0 & 4,28 \\
$\mathbf{9}(\mathbf{C})$ & 0 & 0 & 0 & 40 & 5 & 5 & 8,04 \\
$\mathbf{1 0}(\mathbf{C})$ & 0 & 0 & 0 & 40 & 5 & 5 & 9,56 \\
$\mathbf{1 1}(\mathbf{C})$ & 0 & 0 & 0 & 40 & 5 & 5 & 9,94 \\
\hline
\end{tabular}

*UA = Unidade de Absorbância

Fonte: Própria (2019)

Com os dados obtidos, foi possível verificar que as quantidades de farelo de cevada, GMS e glicina como substratos, atuaram de forma eficaz na produção de pigmentos vermelhos extracelulares, onde a maior produção pôde ser observada no ensaio cujos níveis eram mais altos para as variáveis (ensaio 1), contendo maior quantidade de farelo de cevada, GMS e glicina (60 g/L, $10 \mathrm{~g} / \mathrm{L}$ e $10 \mathrm{~g} / \mathrm{L}$, respectivamente).

Em contrapartida, no ensaio 6 houve uma menor produção de pigmentos, sendo ocasionado pelos níveis mais baixos do substrato, ou seja, as quantidades aplicadas foram as mínimas estabelecidas pelo planejamento fatorial ( $20 \mathrm{~g} / \mathrm{L}$ de farelo de cevada, $0 \mathrm{~g} / \mathrm{L}$ de GMS e $0 \mathrm{~g} / \mathrm{L}$ de glicina). Desta forma, constatou-se efetivamente que o substrato foi fundamental para a obtenção dos pigmentos, bem como comprovando a afinidade da cepa ao meio no qual foi fermentado.

Em seus estudos relacionados à produção de pigmentos utilizando a cepa de Monascus purpureus CCT 3802 empregando farelo de mandioca e GMS como substrato, Silva et al. (2018) também pôde obter uma maior produção em seu experimento em ensaios cujas quantidades de substratos eram maiores, empregando também o comprimento de onda de $510 \mathrm{~nm}$ para quantificar a produção do pigmento. Seu máximo alcance atingiu valores de 7,52 UA empregando o farelo de mandioca (50 g/L) e GMS (10 g/L), como fonte externa de nitrogênio. Sua obtenção de pigmentos também variou de acordo com os ensaios: aqueles que continham menos farelo e GMS produziram menos, quando comparados aos demais.

Em sua produção de biopigmentos, utilizando bagaço de malte como substrato, Oliveira et al. (2016) analisou a velocidade do crescimento radial do Monascus ruber CCT 3802 por meio de cultivo sólido. O estudo foi capaz de comprovar que a maior velocidade de crescimento radial ocorreu sob a maior quantidade de bagaço de malte (40 g/L), capaz de concluir que o fungo mais uma vez mostrou-se compatível com o resíduo cervejeiro utilizado.

O uso de coprodutos industriais para a obtenção de pigmentos também é algo almejado pela biotecnologia, pois a partir deste reaproveitamento é possível produzir algo inovador e com 
valor agregado. Assim como Bühler et al., (2013), que utilizando coprodutos do biodiesel como substrato para a produção por Monascus ruber em biorreator, foram capazes de constatar que a maior obtenção de pigmentos ocorreu a partir da glicerina bruta, proveniente da produção do biodiesel, como substrato, alcançando valores de absorbância de 8,28 UA510.

Também por meio da fermentação submersa de Monascus purpureus, Silveira, Daroit, Brandelli (2007) obtiveram boa produção de pigmentos extracelulares a partir de um resíduo, neste caso, resíduos de uva foram aplicados como substrato, além de peptona e glutamato monossódico como fontes externas de suplementação do meio. Neste caso, a peptona e o resíduo utilizado como substrato apresentaram maior significância na produção final, pois o uso de glutamato monossódico mostrava-se satisfatório apenas quando complementado com concentrações elevadas de resíduo de uva e peptona.

Os efeitos das variáveis independentes analisadas (farelo de cevada, GMS e glicina) e sua atuação sobre a variável de resposta (produção de pigmentos vermelhos) podem ser observadas no gráfico de Pareto (Figura 1).

Figura 1: Gráfico de Pareto dos efeitos das variáveis independentes (farelo de cevada, GMS e glicina) sobre a produção de pigmentos vermelhos no planejamento fatorial $2^{3}$

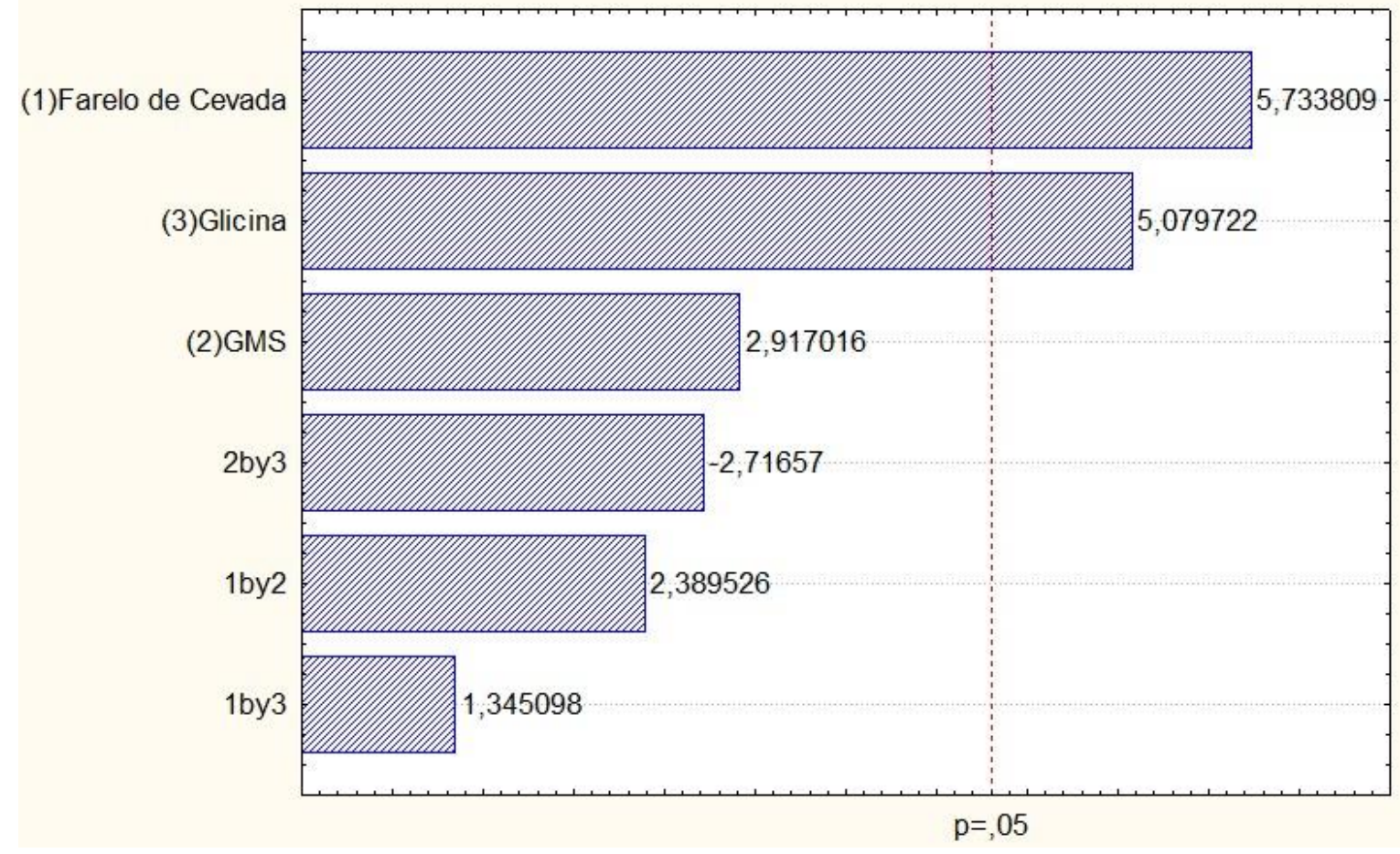

Fonte: Própria (2019)

A partir do gráfico de Pareto, com 95\% de confiança, observa-se que entre as variáveis 
utilizadas, as que mais provocaram efeitos significativos para a produção de pigmentos foram o farelo de cevada e a glicina, respectivamente. Este fato pôde ser comprovado analisando o ensaio 4, cujos níveis de farelo e glicina eram máximos, estabelecidos pelo planejamento (60 $\mathrm{g} / \mathrm{L}$ e $10 \mathrm{~g} / \mathrm{L}$, respectivamente), obtendo-se uma produção elevada quando comparada com os demais ensaios com níveis mais baixos. Estes dados revelam a tendência do próximo planejamento, aumentando as quantidades de farelo de cevada e glicina, a fim de otimizar a produção e adquirir uma quantidade maior de pigmentos. O gráfico também mostra que a variável que exerceu mais influência neste processo foi o farelo de cevada, comprovando que a cepa Monascus purpureus CCT 3802 é capaz de metabolizar resíduos agroindustriais de baixo custo, em especial o farelo de cevada, graças a sua composição química, a qual auxiliou o metabolismo da cepa, propiciando a produção e obtenção dos pigmentos.

\section{Conclusões}

O resíduo agroindustrial estudado (farelo de cevada) juntamente a fonte externa de nitrogênio glicina exerceram influência positiva no planejamento fatorial $2^{3}$ executado, provando que altas concentrações deste no meio se mostraram eficazes na produção estudada, sendo possível a otimização deste processo. Além disso, o fungo Monascus purpureus CCT 3802 mostrou-se adaptável ao meio onde o farelo de cevada se concentrava, graças a sua composição físico-química, rica em proteínas, lipídeos e fibras que estimulam seu metabolismo, auxiliando na maior produção de pigmentos, comprovando que o presente estudo é uma fonte alternativa de tratamento e eliminação deste resíduo da indústria cervejeira do meio ambiente.

\section{Referências}

AMORIM, K.A.; PESSOA, C.E.; ALVES, V.M.; DIAS, L.G.; DAMIANI, C.; DA SILVA, E.P. Granulometria e atividade de água de farinha de trigo, polvilho e trigo moído. XXV Congresso Brasileiro de Ciência e Tecnologia de Alimentos. Alimentação: a árvore que sustenta a vida, Gramado- RS, 2016.

BABITHA, S. Microbial pigments. Biotecnology for agro-industrial residues utilisation, Nova Deli, v. 1, p. 147-162, 2009.

BRASIL. Resolução RDC ANVISA/MS nº. 263, de 22 de setembro de 2005. Regulamento técnico para produtos de cereais, amidos, farinhas e farelos. Diário Oficial da União, Brasília, DF, 23 set. 2005. 
BÜHLER, R.M.M.; DUTRA, A.C.; VENDRUSCOLO, F.; MORITZ, D.E.; NINOW, J.L. Monascus pigment production in bioreactor using a co-product of biodiesel as substrate. Ciência e Tecnologia de Alimentos, Campinas, v.33 (Supl. 1), p.9-13, fev., 2013.

CARVALHO, J. C.; PANDEY, A.; BABITHA, S.; SOCCOL, C. R. Production of Monascus Biopigments: an overview. Agro Food Industry Hi-Technology, v. 14, n. 6, p. 37-42, 2003.

CATALANI, L.; KANG, E.M.S.; DIAS, M.C.G.; MACULEVICIUS, J. Fibras alimentares. Revista Brasileira de Nutrição Clínica, v. 18, n. 4, p. 178-182, 2003.

CONSTANT, P.B.L.; STRINGHETA, P.C.; SANDI, D. Corantes alimentícios. Boletim do Centro de Pesquisa de Processamento de Alimentos. Curitiba- PR, v.20, n.2, p.203-22, jul./dez., 2002.

CORDEIRO, L.G.C. Caracterização e viabilidade econômica do bagaço de malte oriundo de cervejarias para fins energéticos. Dissertação (Mestrado em Química e Bioquímica de Alimentos) - Universidade Federal da Paraíba. João Pessoa. 120 p. 2011.

CORREA, L. C.; DIAS, R. de C.S.; SOUZA, R. de C.R.; MARTINS, S.S; SILVA, P.T. de S. Determinação de betacaroteno e licopeno em frutas e hortaliças por cromatografia líquida de alta eficiência (Cale). Embrapa Semiárido-Boletim de Pesquisa e Desenvolvimento (INFOTECA-E), 2015.

DAMODARAN, S.; PARKIN, K.L. Química de alimentos de Fennema. Artmed Editora, 5 ed., 2018.

DETMANN, E.; SOUZA, M. A.; VALADARES FILHO, S. C.; QUEIROZ, A. C.; BERCHIELLI, T. T.; SALIBA, E. O. S.; CABRAL, L. S.; PINA, D. S.; LADEIRA, M. M.; AZEVEDO, J. A. G. Métodos para análise de alimentos - INCT - Ciência Animal. Visconde do Rio Branco: Suprema, 2012.

GONÇALVES, A.P.; MARTINS, D.S. Caracterização química do bagaço de cevada como matéria-prima em compósitos de amido. $5^{\circ}$ Congresso Brasileiro de Química: Natal, Rio Grande do Norte. 2014.

HALL, M. B. Challenges with nonfiber carbohydrate methods. Journal of Animal Science. v. 81, p. 3226-3232, 2003.

INSTITUTO ADOLFO LUTZ. Métodos físico-químicos para análise de alimentos. 4 . ed. $1^{\circ}$ Edição digital. São Paulo: Instituto Adolfo Lutz, p. 1020, 2008.

MARTINS, N.; $\quad$ CUSTÓDIO,L.R.; MORALES,P.; $\quad$ BARROS,L. Food colorants: Challenges, opportunities and current desires of agroindustries to ensure consumer expectations and regulatory practices. Trends in Food Science \& Technology. v. 52, p. 1-15, 2016.

MATHIAS, T. R. S.; MELLO, P.P.M de; SERVULO, E. F. C. Caracterização de resíduos cervejeiros. In: XX COBEQ-Congresso Brasileiro de Engenharia Química: Florianópolis, Santa Catarina. 2014. 
MAYER, E.T.; FUKE, G.; NORNBERG, J.L.; MINELLA, E. Caracterização nutricional de grãos integrais e descascados de cultivares de cevada. Pesquisa Agropecuária Brasileira. Brasília, v.42, n.11, p.1635-1640, nov., 2007.

MELLO, L.R.P.F.; VERGÍLIO, R.M.; MALI, S. Caracterização química e funcional do resíduo fibroso da indústria cervejeira. Anais do III Simpósio de Bioquímica e Biotecnologia. Biochemistry and Biotechnology Reports, v.2, n.3, p.191-194, 2013.

MUSSATO, S.I.; DRAGONE, G.; ROBERTO, I.C. Brewers' spent grain: generation, characteristics and potential applications. Journal of Cereal Science, v.43, p.1-14, 2006.

OLVERA, F.C.; SANOJA, R.R.; GARCÍA, F.P.; GUTIÉRREZ, A.D.R. Caracterización física y química proximal de paja, grano y almidón de cebada de la variedade esmeralda. BioTecnología, v.16, n.3, p. 9-20, 2012.

OLIVEIRA, C. F.D. Produção de pigmentos por Monascus ruber CCT 3802 a partir do xarope de maltose como substrato. Dissertação (Mestrado em Ciência e Tecnologia de Alimentos) - Universidade Federal de Goiás. Goiânia, 87 p. 2017.

OLIVEIRA, C. F. D.; VENDRULUSCO, F; COSTA, J. P. V.; ARAUJO, W. D. B. Bagaço de malte como substrato para produção de biopigmentos produzidos por Monascus ruber CCT 3802. Revista de Agricultura Neotropical, v. 3, n. 3, p. 6-9, jul./set., 2016.

PRADO, M.A.; GODOY, H.T. Corantes artificiais em alimentos. Alimentos e Nutrição, Araraquara- SP, v. 14, n. 2, p. 237-250, 2009.

RIBEIRO, E.P.; SERAVALLI, E.A.G. Química de Alimentos. Instituto Mauá de Tecnologia. $2^{\mathrm{a}}$ ed. Editora Blucher, p.19, 2007.

ROCHA, D.S.; REED, E. Pigmentos naturais em alimentos e sua importância para a saúde. Revista EVS-Revista de Ciências Ambientais e Saúde, v. 41, n. 1, p. 76-85, 2014.

SCHIOZER, A. L.; BARATA, L.E.S. Estabilidade de corantes e pigmentos de origem vegetal. Revista Fitos, v.3, n.2, p.6-24, 2007.

SILVA, J.R.; SILVA, T.T.; SILVA, E.K.; SILVA, S.P.; RIBEIRO, D.S. Produção de pigmentos de Monascus ruber CCT 3802 utilizando casca de mandioca como substrato. Revista Brasileira de Agrotecnologia, v.8, n.3, p.26-31, 2018.

SILVEIRA, S.T.; DAROIT, D.J.; BRANDELLI, A. Pigment production by Monascus purpureus in grape waste using factorial design. LWT Food Science and Technology, v.41, p.170-174, 2008.

SOUZA, J.M.L.; ÁLVARES, V.S.; LEITE, F.M.N.; REIS, F.S.; FELISBERTO, F.A.V. Caracterização físico-química de farinhas oriundas de variedades de mandioca utilizadas no vale do Juruá, Acre. Acta Amazonica, v.38, n.4, p.761-766, 2008. 
SRIANTA, I.; ZUBAIDAH, E.; ESTIASIH, T.; YAMADA, M.; HARIJONO. Comparison of Monascus purpureus growth, pigment production and composition on different cereal substrates with solid state fermetantion. Biocatalysis and Agricultural Biotechnology, v.7, p. 181-186, 2016.

YALCIN, E.; ÇELIK, S.; AKAR, T.; SAYIM, I.; KOKSEL, $\mathrm{H}$. Effects of genotype and environment on $\beta$-glucan and dietary fiber contents of hullless barleys grown in Turkey. Food Chemistry. v.101, n.1, p.171-176, 2007. 